\title{
Article \\ Combined Effects of Cellulose Nanofiber Nucleation and Maleated Polylactic Acid Compatibilization on the Crystallization Kinetic and Mechanical Properties of Polylactic Acid Nanocomposite
}

\author{
Siti Shazra Shazleen ${ }^{1}{ }^{(\mathbb{D}}$, Lawrence Yee Foong $\mathrm{Ng}^{1}$, Nor Azowa Ibrahim ${ }^{2}{ }^{\mathbb{D}}$, Mohd Ali Hassan ${ }^{3}$ and \\ Hidayah Ariffin 1,3,*ib \\ 1 Laboratory of Biopolymer and Derivatives, Institute of Tropical Forestry and Forest Products (INTROP), \\ Universiti Putra Malaysia, Serdang 43400, Malaysia; shazra.shazleen@yahoo.com (S.S.S.); \\ lawrenceyfng@gmail.com (L.Y.F.N.) \\ 2 Department of Chemistry, Faculty of Science, Universiti Putra Malaysia, Serdang 43400, Malaysia; \\ norazowa@upm.edu.my \\ 3 Department of Bioprocess Technology, Faculty of Biotechnology and Biomolecular Sciences, \\ Universiti Putra Malaysia, Serdang 43400, Malaysia; alihas@upm.edu.my \\ * Correspondence: hidayah@upm.edu.my
}

Citation: Shazleen, S.S.; Foong Ng, L.Y.; Ibrahim, N.A.; Hassan, M.A.; Ariffin, H. Combined Effects of Cellulose Nanofiber Nucleation and Maleated Polylactic Acid Compatibilization on the Crystallization Kinetic and Mechanical Properties of Polylactic Acid Nanocomposite. Polymers 2021, 13, 3226. https://doi.org/10.3390/ polym 13193226

Academic Editor: Jun Xu

Received: 15 July 2021

Accepted: 15 September 2021

Published: 23 September 2021

Publisher's Note: MDPI stays neutra with regard to jurisdictional claims in published maps and institutional affiliations.

Copyright: (c) 2021 by the authors. Licensee MDPI, Basel, Switzerland. This article is an open access article distributed under the terms and conditions of the Creative Commons Attribution (CC BY) license (https:/ / creativecommons.org/licenses/by/ $4.0 /)$.

\begin{abstract}
This work investigated the combined effects of CNF nucleation (3 wt.\%) and PLA-g-MA compatibilization at different loadings (1-4 wt.\%) on the crystallization kinetics and mechanical properties of polylactic acid (PLA). A crystallization kinetics study was done through isothermal and non-isothermal crystallization kinetics using differential scanning calorimetry (DSC) analysis. It was shown that PLA-g-MA had some effect on nucleation as exhibited by the value of crystallization half time and crystallization rate of the PLA/PLA- $g$-MA, which were increased by $180 \%$ and $172 \%$, respectively, as compared to neat PLA when isothermally melt crystallized at $100{ }^{\circ} \mathrm{C}$. Nevertheless, the presence of PLA- $g$-MA in PLA/PLA- $g$-MA/CNF3 nanocomposites did not improve the crystallization rate compared to that of uncompatibilized PLA/CNF3. Tensile strength was reduced with the increased amount of PLA-g-MA. Contrarily, Young's modulus values showed drastic increment compared to the neat PLA, showing that the addition of the PLA-g-MA contributed to the rigidity of the PLA nanocomposites. Overall, it can be concluded that PLA/CNF nanocomposite has good performance, whereby the addition of PLA-g-MA in PLA/CNF may not be necessary for improving both the crystallization kinetics and tensile strength. The addition of PLA- $g$-MA may be needed to produce rigid nanocomposites; nevertheless, in this case, the crystallization rate of the material needs to be compromised.
\end{abstract}

Keywords: cellulose nanofiber; nucleating agent; crystallization rate; polylactic acid; compatibilizer

\section{Introduction}

Most items in the market are packed for various purposes such as protection, storage, preservation, transportation and presentation. The consumption of packaging is high in both food and non-food industries. A wide range of materials can be used for packaging applications such as glass, paper and petroleum-based polymers. In regard to their versatility and outstanding characteristics, petroleum-based plastics have been widely used for various purposes. Nevertheless, these plastics can only be used once before they are thrown out, as these materials are non-biodegradable and recycling or reusing them is a very challenging task, causing the generation of a huge amount of non-biodegradable wastes [1]. Therefore, the use of these polymers has been restricted due to the expensive recycling methods and limitations of disposal methods as well as adequate landfill problems [2]. By shifting to biodegradable polymers to replace synthetic polymers, environmental pollution caused by the accumulation of non-biodegradable synthetic plastics can be reduced 
significantly. Moreover, consumer demand for products that are environmentally friendly, safer and non-toxic along with a currently advantageous economic scenario leads to the assumption that biodegradable packaging materials will become increasingly prevalent [3]. Hence, biodegradable polymers are often used as an alternate material to replace synthetic polymers.

Biodegradable polymers have attracted many attentions as a potential replacement for petro-plastic packaging, but it is relatively poor material since most of it is made from biological sources and their properties are not as excellent as synthetic plastic, which limits its usage in industry [4]. Nevertheless, polylactic acid (PLA) polymer has gained a lot of interest as one of the most promising alternatives to synthetic polymers, as its properties are comparable to those of polystyrene and, as a result, it is used in large quantities, particularly in packaging applications [5-7].

PLA is a versatile material and has been favored because it can be mass-produced from renewable agricultural raw materials that are fermented into lactic acid, thereby reducing the reliance of society on petrochemical feedstocks. PLA can be considered as an attractive sustainable alternative to petroleum-based plastic since it can be processed using the same machinery where it can be molded, vacuum formed, blown or extruded as easily as conventional plastic [8]. Nevertheless, the use of PLA in commercial applications is still limited mainly due to its high production cost, brittleness, low thermal stability and low gas barrier properties [9]. Additionally, PLA has a slow crystallization rate due to high molecular weight that makes it relatively difficult to utilize as a main material using a common industrial process such as injection molding due to molded PLA mostly amorphous in these rapid processes. Therefore, PLA processing requires longer molding cycles and causes difficulties in demolding section [10]. It is crucial to enhance the crystallization rate of PLA and optimize it to achieve the desired final properties of products for industrial applications. These limitations give a negative effect on the crystallization and mechanical properties of the PLA. Many have attempted to overcome these limitations by various methods, the most common being the addition of reinforcing materials which also can act as nucleating agents such as graphene [11,12], talc [13-15] and natural fibers [16-19]. These additives have been successfully used as nucleating agents and have proven to show an enhancement in the crystallization kinetics and mechanical properties of PLA.

Nanocellulose has recently gained much attention due to its outstanding properties and applicability in various fields. In fact, nanocellulose is expected to have great potential to replace many non-renewable materials as cellulose materials are the most abundant biological and multifunctional raw materials that can also be self-assembled into well-defined multi-scale architectures, from micro to nanosize [20]. One of the most widely utilized nanocellulose is cellulose nanofiber (CNF) including as reinforcement in nanocomposites [21-28] and can also act as a nucleating agent for improving crystallization behaviors of the polymer matrix [6,29-31]. CNF has been proven to be an effective nucleating agent to enhance the crystallization behaviors of the polymer matrix as compared to microsized cellulose fibers [30]. CNF allows for a heterogeneous nucleation process that promotes a decrease of the free energy barrier and accelerates the crystallization rate [9]. The addition of CNF could also increase the number of nucleation sites and decrease the crystal size with an increased nucleation density [32]. Moreover, CNF has been utilized globally in industrial application owing to its outstanding properties including; high flexibility, high in mechanical strength, high crystallinity, high aspect ratio and renewability that can be produced by mechanical or chemical treatments that are advantageous for nanocomposites and reinforced polymers [33,34].

Although CNF has gained substantial market interest as an alternative to inorganic nano-sized reinforcements in nanocomposite materials, the main challenge of using nanofiber is the difficulties of achieving good nanofiber dispersion in a non-polar medium due to their polar surfaces [35]. CNF has been shown to be compatible with PLA based on previous studies, but agglomeration was observed to occur at a certain amount of CNF, notably at higher loading. Difficulties of PLA to interact with reinforcements containing polar moieties 
owing to its non-polar nature resulting in poor nanofiller dispersion, insufficient adhesion and reduced its properties. This creates a major drawback for PLA nanocomposites because they are unable to achieve their maximum performance ability. To extent their industrial applications, CNF must overcome their weak interfacial compatibility with PLA matrix. An alternative approach is to blend the PLA matrix with CNF in the presence of compatibilizer. Compatibilization method has the capability to improve the mechanical properties by grafting monomers to the polymer backbone [36]. Compatibilizer can be produced through free-radical copolymerization or grafting of the reactive group onto polymer chains during the compounding process [37]. Several compatibilizers have been studied and used in previous researches to compatible with PLA blends (i.e., starch, talc) including dioctyl maleate (DOM) [38], methylenediphenyl diisocyanate (MDI) [32,39-41] and glycidyl methacrylate (GMA) grafted PLA (PLA-g-GMA) [42].

Nowadays, maleated PLA (PLA-g-MA) has been widely used as a compatibilizer between PLA and CNF. PLA- $g$-MA can be prepared by grafting maleic anyhydride (MA) onto PLA chains in the presence of peroxides as an initiator to create reactive sites for MA to graft. Compatibilization achieved by the addition of PLA-g-MA produced through reactive extrusion is an effective way of manufacturing nanocomposites at high production rates and therefore economically feasible on an industrial scale [43]. Previous research conducted by Ghasemi et al. [44] has observed improvements in tensile strength, modulus and impact strength of PLA/CNF5 by 55, 15 and 40 while PLA/CNF5/PLA-g-MA5 by 169, 40 and $131 \%$ as compared to neat PLA, respectively. This increment might be attributed to compatibilizer impact on enhancing interfacial adhesion between two phases: CNF and PLA matrix. Additionally, the results obtained from heat distortion temperature study indicated that the addition of PLA-g-MA had a positive effect on the thermal stability of PLA nanocomposites.

In the previous research, we investigated the optimal PLA and CNF blending ratio to achieve the maximal crystallization rate and mechanical properties for PLA nanocomposites [45]. In this article, we study the PLA nanocomposites blended with $3 \mathrm{wt} . \%$ of $\mathrm{CNF}$ with the addition of PLA-g-MA as a compatibilizer. It is evident from the literature review that no research has been conducted on the combination effects of nucleation and compatibilization between CNF and PLA-g-MA and their correlation to improve the crystallization and mechanical properties of PLA. Hence, in this study we intend to enhance the crystallization and compatibility of nanocomposites through the combination effects of CNF nucleation and PLA-g-MA compatibilization to increase the crystallization rate and to optimize the interfacial interaction between PLA and CNF to improve the mechanical performances.

\section{Materials and Methods}

\subsection{Materials}

Polylactic acid (PLA) (grade 2003D, NatureWorks LLC, Minnetonka, MN, USA) in pellet form was purchased from Ecoscience Sdn. Bhd with melt flow index of $6.0 \mathrm{~g} / 10 \mathrm{~min}$ at $210{ }^{\circ} \mathrm{C}$ was used as is. The number- and weight-average molecular weights $\left(\mathrm{M}_{\mathrm{n}}\right.$ and $\mathrm{M}_{\mathrm{w} \text {, respectively }}$ ) and polydispersity index (PDI; calculated as the ratio of $\mathrm{M}_{\mathrm{w}} / \mathrm{M}_{\mathrm{n}}$ ) of $165,189 \mathrm{~g} / \mathrm{mol}, 76,066 \mathrm{~g} / \mathrm{mol}$ and 2.17 was determined by gel permeation chromatograpy (GPC) at $40{ }^{\circ} \mathrm{C}$ using THF as eluant on a Waters apparatus (USA) equipped with three columns Styragel HR1, HR3 and HR5 and with a Waters 2414 refractive index detector at an eluation rate of $1 \mathrm{~mL} / \mathrm{min}$. The system was calibrated using polystyrene standards. Cellulose nanofiber (CNF) with a concentration of $2 \mathrm{wt}$ \% fiber slurry was purchased from ZoepNano Sdn. Bhd. Maleic anhydride (MA) and dibenzoyl peroxide (DBPO) were purchased from Synergy Scientific Sdn. Bhd, while methanol, chloroform and hydrochloric acid $(\mathrm{HCl})$ were purchased from Greenfinite Sdn. Bhd. All chemicals were used as received. 


\subsection{Methods}

MA was grafted onto PLA by the melt-blending method using an internal mixer, Brabender Plasticoder (Brabender Messtechnik GmbH Co., Duisburg, Germany) at $160{ }^{\circ} \mathrm{C}$ for $15 \mathrm{~min}$ with a rotor speed of $70 \mathrm{rpm}$, in accordance with the method modified from Birnin-yauri et al. [46] and Calderón et al. [37]. PLA resin was oven-dried at $60^{\circ} \mathrm{C}$ overnight prior to mixing to prevent hydrolytic degradation melt compounding. The compatibilizer at 3 and $10 \mathrm{wt} . \%$ of MA were prepared by melting the oven-dried PLA resins for $5 \mathrm{~min}$ followed by the addition of DBPO as an initiator and mixed for an additional $2 \mathrm{~min}$. Finally, MA was added and mixed continuously for another $8 \mathrm{~min}$, resulting in the production of PLA-g-MA. The composition of PLA, MA and DBPO are tabulated in Table 1.

Table 1. Compositions of PLA, MA and DBPO for PLA-g-MA production.

\begin{tabular}{cccc}
\hline PLA-g-MA & \multicolumn{3}{c}{ Composition (wt.\%) } \\
\cline { 2 - 4 } (MA wt.\%) & Polylactic Acid (PLA) & Maleic Anhydride (MA) & Dibenzoyl Peroxide (DBPO) \\
\hline 3 & 36.25 & 3 & 0.75 \\
10 & 29.25 & 10 & 0.75 \\
\hline
\end{tabular}

The PLA-g-MA, yellow color strips was removed and then ground into small pieces with a grinder. The unreacted MA and DBPO were eliminated from the compatibilizer by placing it in a vacuum oven at $80^{\circ} \mathrm{C}$ overnight.

Purification was done by dissolving $2.0 \mathrm{~g}$ of PLA-g-MA in $40 \mathrm{~mL}$ chloroform, followed by addition of $0.75 \mathrm{~mL}$ of $1 \mathrm{M} \mathrm{HCl}$ at room temperature to hydrolyze the anhydride into carboxylic acid. The mixture was then stirred for $1 \mathrm{~h}$ and drop-wise added into $400 \mathrm{~mL}$ methanol. The filtered precipitate was rinsed with methanol several times, and vacuum oven-dried at $80{ }^{\circ} \mathrm{C}$ overnight. Next, direct titration was carried out to determine the degree of MA grafting onto PLA. A total of $0.4 \mathrm{~g}$ of the purified sample was dissolved in $20 \mathrm{~mL}$ chloroform and titrated against $0.04 \mathrm{M}$ methanolic $\mathrm{NaOH}$ using phenolphthalein as an indicator. Degree of grafting was calculated using the equation:

$$
\text { MAgrafting }(\%)=\frac{\mathrm{N}_{\mathrm{NaOH}} \cdot \mathrm{V}_{\mathrm{NaOH}}}{2 \times \mathrm{m}_{\text {sample }}} \times 98.06 \times 100
$$

where $\mathrm{N}_{\mathrm{NaOH}}$ and $\mathrm{V}_{\mathrm{NaOH}}$ indicate the volume (L) and normality $(\mathrm{mol} / \mathrm{L})$ of $\mathrm{NaOH}$ and $\mathrm{m}_{\text {sample }}$ is the sample weight $(\mathrm{g})$. The sample was determined three times and the average degree of grafting was reported.

The grafting efficiency of PLA-g-MA was calculated using the equation:

$$
\text { Grafting efficiency }(\%)=\frac{\text { weight of grafted monomer }}{\text { weight of loaded monomer }} \times 100
$$

where the weight of the grafted monomer was obtained by multiplying MA grafting percentage with sample weight $\left(\mathrm{m}_{\text {sample }}\right)$ and the weight of loaded monomer indicate the feeding weight of anhydride monomers.

Fourier transform infrared spectroscopy (FTIR) was conducted on the PLA pellet, pure MA and purified PLA-g-MA to monitor the grafting process of MA onto PLA backbone using a Perkin Elmer Spectrum 100 series spectrophotometer (Waltham, MA, USA), which was equipped with an attenuated total reflectance (ATR) capacity at a wavenumber range of $500-4000 \mathrm{~cm}^{-1}$.

Solid-state ${ }^{13} \mathrm{C}$ NMR nuclear magnetic resonance spectra were recorded on a $500 \mathrm{MHz}$ NMR spectrometer (JOEL, model JNM-ECX500). The spectra for neat PLA and purified PLA-g-MA (10\% of MA) were obtained by 2048 scans in a spectral width of $200 \mathrm{ppm}$ and the number of raw data points was 6144 . 


\section{Preparation of Nanocomposites}

Nanocomposites neat PLA, PLA/PLA-g-MA3/CNF0 and PLA/PLA- $g-M A / C N F 3$ with different PLA-g-MA loading were prepared using the same method as described in our previous study Shazleen et al. [45]. Prior to mixing, moisture from PLA pellets was removed by drying at $60^{\circ} \mathrm{C}$ for $24 \mathrm{~h}$ under vacuum condition to minimize hydrolytic degradation during the melt compounding at high temperature. The dried PLA pellets were mixed with $3 \mathrm{wt} . \% \mathrm{CNF}$ and PLA-g-MA at different contents $(1-4 \mathrm{wt} . \%)$ at $170{ }^{\circ} \mathrm{C}$ for $30 \mathrm{~min}$ with a rotor speed of $70 \mathrm{rpm}$. The composition of PLA, PLA- $g$-MA and CNF for nanocomposites are as tabulated in Table 2.

Table 2. Sample codes and compositions of PLA/PLA-g-MA/CNF nanocomposites.

\begin{tabular}{cccc}
\hline \multirow{2}{*}{ Sample } & \multicolumn{3}{c}{ Composition (wt.\%) } \\
\cline { 2 - 4 } & Polylactic Acid (PLA) & Maleated PLA (PLA-g-MA) & Cellulose Nanofiber (CNF) \\
\hline Neat PLA & 100 & 0 & 0 \\
PLA/PLA-g-MA3/CNF0 & 97 & 3 & 0 \\
PLA/PLA-g-MA0/CNF3 & 97 & 0 & 3 \\
PLA/PLA-g-MA1/CNF3 & 97 & 1 & 3 \\
PLA/PLA-g-MA2/CNF3 & 95 & 2 & 3 \\
PLA/PLA-g-MA3/CNF3 & 97 & 3 & 3 \\
PLA/PLA-g-MA4/CNF3 & 96 & 4 & 3 \\
\hline
\end{tabular}

\subsection{Characterization}

\subsubsection{Crystallization Kinetics Analysis}

Non-isothermal and isothermal crystallization behaviors of the nanocomposites were characterized using DSC (Q200, TA Instruments, New Castle, DE, USA). Indium was used as standard calibration for temperature and heat of fusion. Sample weighing between 7 to $10 \mathrm{mg}$ was used for the measurement.

For non-isothermal crystallization, the samples were first heated from $30{ }^{\circ} \mathrm{C}$ to $190{ }^{\circ} \mathrm{C}$ at a rate of $2{ }^{\circ} \mathrm{C} / \mathrm{min}$ and maintained at this temperature for $3 \mathrm{~min}$ to remove the prior thermal history of the samples. The samples were then cooled to $-40{ }^{\circ} \mathrm{C}$ at the same rate and held at that temperature for $3 \mathrm{~min}$ to evaluate their ability to crystallize upon cooling. Subsequently, the samples were reheated to $190{ }^{\circ} \mathrm{C}$ at the same rate.

For isothermal crystallization, the samples were firstly heated to $190{ }^{\circ} \mathrm{C}$ at a rate of $10{ }^{\circ} \mathrm{C} / \mathrm{min}$ and maintained at this temperature for $3 \mathrm{~min}$ to remove their prior thermal history. The samples were then rapidly cooled to the isothermal crystallization temperature of 90,100 and $110^{\circ} \mathrm{C}$ at a rate of $50^{\circ} \mathrm{C} / \mathrm{min}$ and maintained at this temperature until the crystallization process in the samples was completed.

\subsubsection{Mechanical Analysis}

Tensile strength (MPa), elongation at break (\%), and Young's modulus (GPa) were measured by using an Instron 5566 Universal Testing Machine (Norwood, MA, USA) with a load cell of $10 \mathrm{kN}$ and crosshead speed of $5 \mathrm{~mm} / \mathrm{min}$ at room temperature. Five dog-bone shaped specimens, each with a $3 \mathrm{~mm}$ thickness, were tested according to the standard method of ASTM D 638-05.

\subsubsection{Morphological Analysis}

The morphology of the fracture surfaces of the neat PLA, PLA/PLA-g-MA3/CNF0 and PLA/PLA-g-MA/CNF3 nanocomposites from tensile testing were observed using a field emission scanning electron microscope FESEM (FEI Nova NanoSEM 230, Hillsborough, OR, USA). The acceleration voltage used was $5 \mathrm{kV}$, and samples were sputter-coated with gold prior to FESEM observation to avoid charging. 


\section{Results and Discussion}

\subsection{Grafting Analysis and Characterization of PLA-g-MA}

The grafting percentage and efficiency of PLA-g-MA samples with 3 and $10 \mathrm{wt} . \%$ of MA content were determined by the titration method and the data obtained were tabulated in Table 3.

Table 3. Effect of MA content on grafting percentage and efficiency of PLA-g-MA.

\begin{tabular}{ccc}
\hline PLA-g-MA (MA wt.\%) & MA Grafting (\%) & Grafting Efficiency (\%) \\
\hline 3 & $0.15 \pm 0.0$ & $3.13 \pm 0.4$ \\
10 & $2.10 \pm 0.3$ & $13.20 \pm 2.2$ \\
\hline
\end{tabular}

Findings from this analysis revealed that the grafting percentage and efficiency increased by increasing the MA content. The addition of $3 \mathrm{wt} . \%$ MA in PLA resulted in $0.15 \%$ of MA grafting and 3.13\% grafting efficiency. The reason behind the low percentage of MA grafting was due to insufficient amount of MA that could be grafted onto PLA chain, thus leading to low grafting efficiency. Further increasing the MA content to $10 \mathrm{wt} . \%$ resulted in increasing the grafting degree and efficiency to 2.10 and $13.2 \%$, respectively. This shows that increasing the MA content able to increase the possibility of PLA macroradicals generated from the reaction between PLA and DBPO (initiator) to interact with MA to form MA grafted PLA and thus increasing the grafting degree and efficiency [47]. This observation was also reported by Syazana et al. [48]. Muenprasat et al. [49] found that the grafting percentage was not significantly changed when the MA concentration exceeded $10 \mathrm{wt} . \%$ that might be attributed with the occurrence of PLA chain scission reaction at higher MA content and it could compete with the grafting reaction. Since the composition of the DBPO was constant in this study, any variations in grafting degree is attributable to the changes in MA content. The PLA-g-MA with the highest grafting degree and efficiency was used to prepare PLA/PLA-g-MA/CNF3 nanocomposites.

The grafting reaction of MA on PLA backbone has been observed through FTIR analysis where it was performed on neat PLA, pure MA and purified PLA-g-MA samples. The FTIR spectra are depicted in Figure 1.

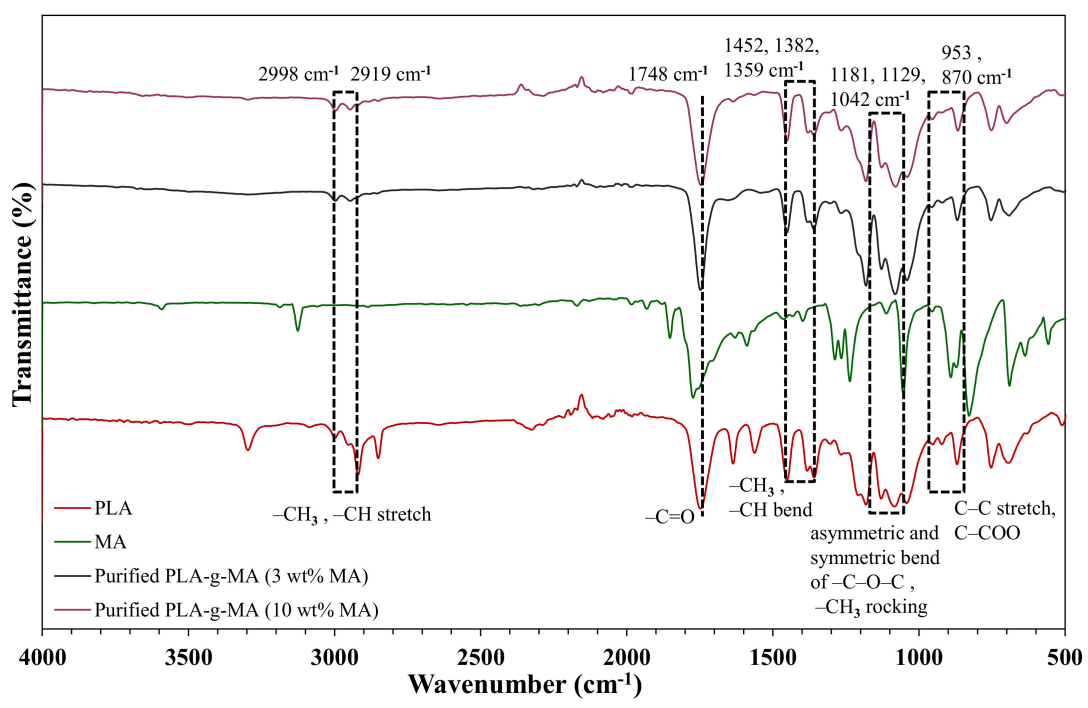

Figure 1. FTIR spectra of neat PLA, pure MA and purified PLA-g-MA at 3 and $10 \mathrm{wt} \%$ of MA.

Neat PLA exhibit characteristic transitions at 2998 and $2919 \mathrm{~cm}^{-1}\left(-\mathrm{CH}_{3}\right.$ and $-\mathrm{CH}$ stretching vibrations), $1748 \mathrm{~cm}^{-1}(-\mathrm{C}=\mathrm{O}), 1452,1382$ and $1359 \mathrm{~cm}^{-1}\left(-\mathrm{CH}_{3}\right.$ and $-\mathrm{CH}$ bending vibrations), $1266 \mathrm{~cm}^{-1}$ (stretching vibration of -C-O-C), 1181, 1129 and $1042 \mathrm{~cm}^{-1}$ (asymmetric and symmetric bending vibrations of $-\mathrm{C}-\mathrm{O}-\mathrm{C}$ and $-\mathrm{CH}_{3}$ rocking), $953 \mathrm{~cm}^{-1}$ 
(C-C stretching vibration) and $870 \mathrm{~cm}^{-1}$ (C-COO) [50]. The FTIR spectra of purified PLA$g$-MA was almost identical to FTIR spectra of neat PLA, but the only difference that can be noted was the decrease in the intensity of the absorption bands at 2998, 2947, 1452, 1382, and $1359 \mathrm{~cm}^{-1}$. This phenomenon could be attributed to the -CH group of PLA main-chain involved in the grafting reaction, thus confirming that the grafting reaction has occurred. Nevertheless, the absorption peaks of MA at 1780 and $1850 \mathrm{~cm}^{-1}$ on PLA-g-MA that correspond to symmetric and asymmetric stretching carbonyl groups of cyclic MA were not detected by FTIR as opposed to the spectrum of pure MA and PLA-g-MA that could be due to the overlapping of carbonyl stretching signal present in both grafted MA and PLA backbone [18].

For this reason, solid state ${ }^{13} \mathrm{C}$ NMR analysis has been performed to verify the occurrence of grafting reaction. PLA-g-MA with $10 \mathrm{wt} . \%$ of MA was selected due to its higher percentage grafting and efficiency. Figure 2 shows the ${ }^{13} \mathrm{C}$ NMR spectrum of neat PLA and PLA-g-MA (10 wt.\% of MA) samples.
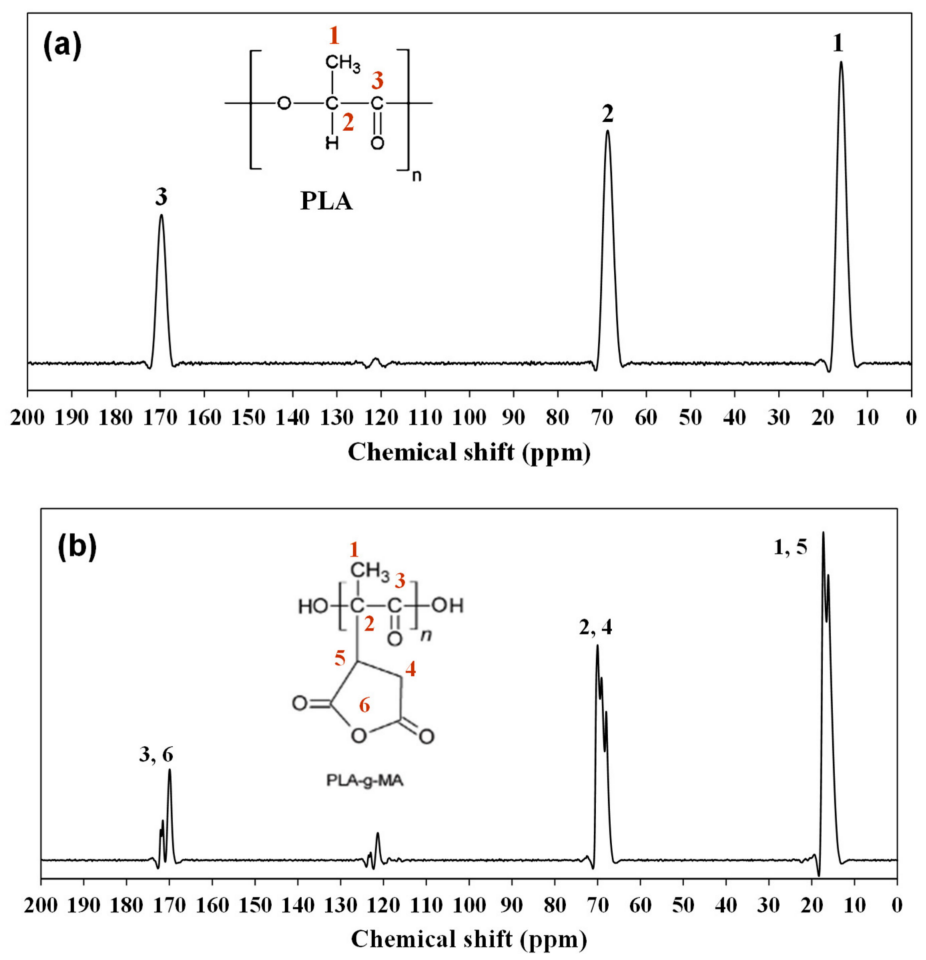

Figure 2. ${ }^{13} \mathrm{C}-\mathrm{NMR}$ spectrum of (a) PLA and (b) purified PLA-g-MA at $10 \mathrm{wt} . \%$ of MA.

Here, characteristic signals of PLA are observed at 169.8, 68.6 and 15.8 ppm referring to carbonyl $(-\mathrm{C}=\mathrm{O})$, methine $(-\mathrm{CH})$ and methyl carbons $\left(-\mathrm{CH}_{3}\right)$, respectively. In the PLA-gMA spectrum, succinic anhydride signals (methine, $-\mathrm{CH}$ and methylene carbons, $-\mathrm{CH}_{2}$ ) are not observable that may be due to overlapping of their signals with PLA chemical shifts. However, the presence of MA in PLA could be indirectly demonstrated by the two peaks observed at 16.2 and $17.4 \mathrm{ppm}$ as well as three peaks in the range of $68-72 \mathrm{ppm}$ and $170-180 \mathrm{ppm}$. The separation of signals can be attributed to the different chemical environments of PLA resulting from the inequivalent level of grafting [51]. Gross et al. [52] report signals similar as reported in this study.

\subsection{Non-Isothermal Crystallization Kinetics}

The combination effects of CNF nucleation and PLA-g-MA compatibilization at different PLA-g-MA content on the crystallization kinetics of PLA/CNF3 nanocomposites was compared using DSC measurements. Figure $3 b$,c show the non-isothermal DSC cooling curves and subsequent heating curves of neat PLA, PLA/PLA-g-MA3/CNF0 and 
PLA/PLA-g-MA/CNF3 nanocomposite samples at different PLA-g-MA content (0-4 wt.\%). Table 4 summarizes thermal properties of the nanocomposites estimated from the DSC curves including glass transition temperature $\left(T_{g}\right)$, crystallization peak temperature $\left(T_{c}\right)$, cold crystallization peak temperature $\left(\mathrm{T}_{\mathrm{cc}}\right)$, melting peak temperatures $\left(\mathrm{T}_{\mathrm{m} 1}, \mathrm{~T}_{\mathrm{m} 2}\right)$, enthalpy of crystallization $\left(\Delta \mathrm{H}_{\mathrm{c}}\right)$, enthalpy of cold crystallization $\left(\Delta \mathrm{H}_{\mathrm{cc}}\right)$, enthalpy of fusion $\left(\Delta \mathrm{H}_{\mathrm{m}}\right)$ and degree of crystallinity $\left(X_{c}\right)$. The degree of crystallinity $\left(X_{c}\right)$ for neat PLA, PLA/PLA-gMA3/CNF0 and PLA/PLA-g-MA/CNF3 nanocomposites were calculated as follows:

$$
\mathrm{X}_{\mathrm{c}}=\frac{\Delta \mathrm{H}_{\mathrm{m}}-\Delta \mathrm{H}_{\mathrm{cc}}}{\Delta \mathrm{H}_{\mathrm{m}}^{\circ}} \times 100 \%
$$

where $\Delta \mathrm{H}_{\mathrm{m}}$ is the enthalpy of melting, $\Delta \mathrm{H}_{\mathrm{cc}}$ is the crystallization enthalpy during the DSC scan and $\Delta \mathrm{H}^{\circ}{ }_{\mathrm{m}}$ is the enthalpy of melting of $100 \%$ crystalline PLA $\left(\Delta \mathrm{H}^{\circ}{ }_{\mathrm{m}}\right.$ of PLA $\left.=93.7 \mathrm{~J} \mathrm{~g}^{-1}\right)$.

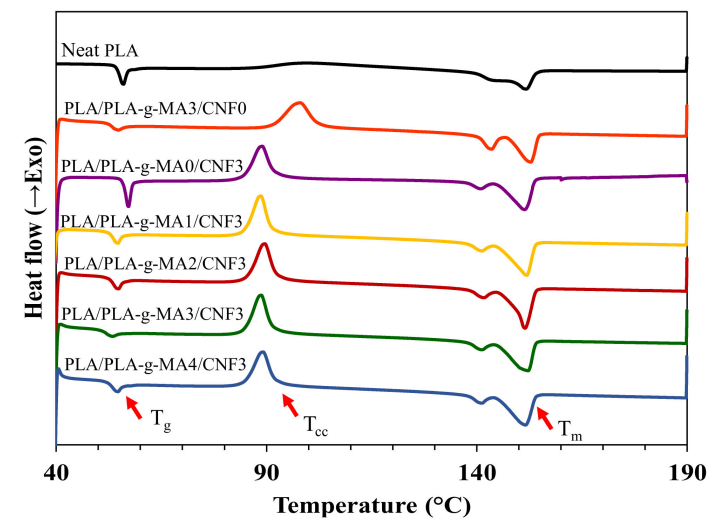

(a)

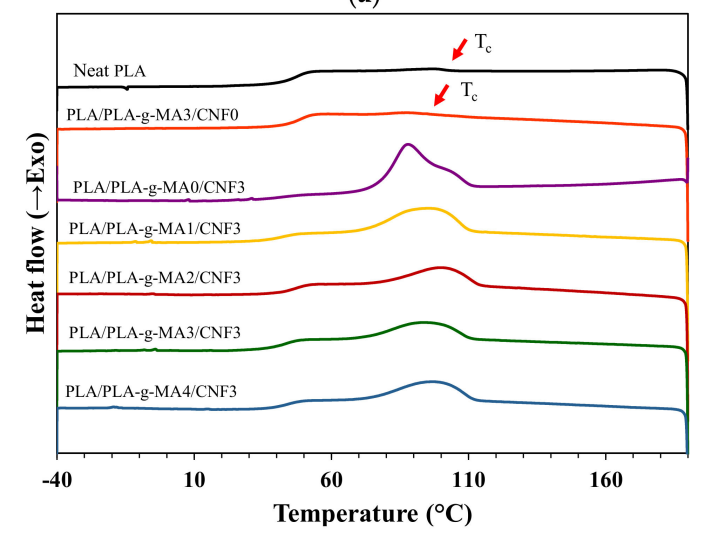

(b)

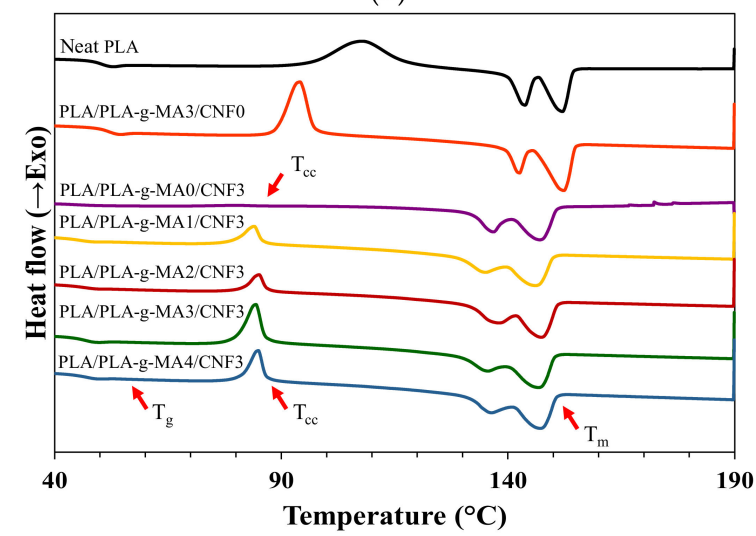

(c)

Figure 3. DSC curves at $2{ }^{\circ} \mathrm{C} / \mathrm{min}$ for neat PLA, PLA/PLA- $g-M A 3 / C N F 0$ and PLA/PLA- $g$ MA/CNF3 nanocomposites: (a) first heating scans, (b) cooling scans and (c) subsequent heating scan. 
Table 4. Non-isothermal crystallization data of neat PLA and PLA/PLA-g-MA/CNF nanocomposites.

\begin{tabular}{cccccccccc}
\hline Sample & $\mathbf{T}_{\mathbf{g}}\left({ }^{\circ} \mathbf{C}\right)$ & $\mathbf{T}_{\mathbf{c}}\left({ }^{\circ} \mathbf{C}\right)$ & $\mathbf{T}_{\mathbf{c c}}\left({ }^{\circ} \mathbf{C}\right)$ & $\mathbf{T}_{\mathbf{m} 1}\left({ }^{\circ} \mathbf{C}\right)$ & $\mathbf{T}_{\mathbf{m} 2}\left({ }^{\circ} \mathbf{C}\right)$ & $\Delta \mathbf{H}_{\mathbf{c}}(\mathbf{J} / \mathbf{g})$ & $\Delta \mathbf{H}_{\mathbf{c c}}(\mathbf{J} / \mathbf{g})$ & $\Delta \mathbf{H}_{\mathbf{m}}(\mathbf{J} / \mathbf{g})$ & $\mathbf{X}_{\mathbf{c}}(\%)$ \\
\hline Neat PLA & 50.4 & 106.1 & 91.3 & 143.5 & 152.1 & 1.3 & 33.4 & 35.6 \\
PLA/PLA-g-MA3/CNF0 & 51.9 & 96.5 & 84.5 & 142.6 & 152.3 & 2.0 & 27.1 & 33.9 \\
PLA/PLA-g-MA0/CNF3 & 43.9 & 114.6 & 71.0 & 136.7 & 147.1 & 33.6 & 0.9 & 42.3 \\
PLA/PLA-g-MA1/CNF3 & 45.9 & 112.7 & 75.5 & 135.3 & 146.1 & 24.5 & 8.8 & 35.4 \\
PLA/PLA-g-MA2/CNF3 & 46.1 & 115.1 & 78.5 & 137.1 & 147.4 & 29.0 & 7.4 & 35.3 & 28.4 \\
PLA/PLA-g-MA3/CNF3 & 46.3 & 113.8 & 75.8 & 135.3 & 146.6 & 16.8 & 14.1 & 41.6 \\
PLA/PLA-g-MA4/CNF3 & 47.3 & 113.3 & 77.9 & 136.1 & 147.0 & 21.1 & 12.4 & 41.0 \\
\hline
\end{tabular}

It can be seen from cooling curves in Figure $3 \mathrm{~b}$ and the data in Table 4 that the crystallization peak of neat PLA and PLA/PLA-g-MA3/CNF0 were almost unnoticeable and exhibits low crystallization enthalpy below $2 \mathrm{~J} / \mathrm{g}$. The onset crystallization temperature $\left(\mathrm{T}_{\mathrm{c}}\right)$ for neat PLA decreased by about $10{ }^{\circ} \mathrm{C}$ from $106.1{ }^{\circ} \mathrm{C}$ to $96.5{ }^{\circ} \mathrm{C}$ when only PLA-gMA was added to the matrix indicating the introduction of PLA-g-MA can hinder the crystallization of PLA, which could be due to the disturbance of the regularity of PLA chains [11]. This is in contrary to the CNF addition in which it is seen that the addition of 3 wt.\% CNF without the presence of PLA-g-MA led to the formation of clear and sharp crystallization peak upon cooling, with high $\Delta \mathrm{H}_{\mathrm{c}}$ at $33.6 \mathrm{~J} / \mathrm{g}$. The onset $\mathrm{T}_{\mathrm{c}}$ was also noticeably increased by almost $8{ }^{\circ} \mathrm{C}$, from $106.1^{\circ} \mathrm{C}$ (neat PLA) to $114.6^{\circ} \mathrm{C}$. This indicates that the nucleation effect of CNF effectively accelerates crystallization process to occur during cooling as reported by Kotsilkova et al. [53]. Effect of PLA-g-MA addition on PLA/CNF3 nanocomposites was determined by incorporating 1-4 wt.\% of PLA-g-MA in the nanocomposite. Based on Figure $3 \mathrm{~b}$ and Table 4, it is seen that the addition of PLA-g-MA generally did not improve the $\mathrm{T}_{\mathrm{c}}$ as compared to the uncompatibilized PLA/CNF3.

In the subsequent heating process, $\mathrm{T}_{\mathrm{g}}$ of neat PLA was observed at $50.4^{\circ} \mathrm{C}$ as shown in Figure $3 \mathrm{c}$ and Table 4 . Reinforcement of $3 \mathrm{wt} . \% \mathrm{CNF}$ reduced the $\mathrm{T}_{\mathrm{g}}$ to $43.9^{\circ} \mathrm{C}$, indicating an increase in PLA chain mobility that resulted in better flexibility. Meanwhile, it was discovered that by solely introducing PLA- $g$-MA to PLA matrix, the $\mathrm{T}_{\mathrm{g}}$ increased slightly to $51.9^{\circ} \mathrm{C}$. In the case of PLA/PLA-g-MA/CNF3 nanocomposites, it was found that the $\mathrm{T}_{\mathrm{g}}$ increased with PLA- $g$-MA content, and the overall $\mathrm{T}_{\mathrm{g}}$ for these nanocomposites was higher as compared to PLA/CNF3. This could be explained by the restriction of molecular motion when anhydride carboxyl group was grafted onto the PLA, which increased the nanocomposites rigidity. Similar observation was reported by $\mathrm{Wu}$ [17].

In all nanocomposites, the $\mathrm{T}_{\mathrm{cc}}$ and $\Delta \mathrm{H}_{\mathrm{cc}}$ were lower as compared to neat PLA. This demonstrates that neat PLA had a slower crystallization process and was unable to crystallize properly during cooling (as shown in Figure 3b). Addition of CNF and PLA-g-MA generally reduced the $\Delta \mathrm{H}_{\mathrm{cc}}$, and the effect was more remarkable with the addition of CNF as compared to PLA-g-MA.

For melting behavior, neat PLA, PLA/PLA-g-MA3/CNF0, uncompatibilized and compatibilized PLA/CNF3 nanocomposites showed bimodal melting peaks as seen in Figure $3 \mathrm{c}$ with $\mathrm{T}_{\mathrm{m} 1}$ at the first melting point (at a lower melting temperature) and $\mathrm{T}_{\mathrm{m} 2}$ at the subsequent peak (at a higher melting temperature). The double endothermic peaks were attributed to melting-recrystallization-melting processes of PLA lamellae. The first peak was observed at around $135-143{ }^{\circ} \mathrm{C}$ and the other at $146-152{ }^{\circ} \mathrm{C}$. The addition of only CNF or in combination with PLA-g-MA did not change melting temperatures much differently between these nanocomposites.

The degree of crystallinity, $X_{c}$, for neat PLA, PLA/PLA-g-MA3/CNF0 and PLA/PLA$g$-MA/CNF3 were calculated and tabulated in Table 4 . The $X_{c}$ of neat PLA was only $2.3 \%$, whereas the addition of PLA- $g$-MA alone in the matrix increased nanocomposites crystallinity to $6.7 \%$. The PLA/CNF3 alone recorded the highest $X_{c}$ of $44.2 \%$ with an almost 95\% increment relative to neat PLA. Nevertheless, the introduction of PLA-g-MA to PLA/CNF3 nanocomposites resulted in the reduction of crystallinity as compared to uncompatibilized sample. This might be due to irregular MA chain branching to PLA 
backbone, thus reduce the regularity of PLA chains and hinder the crystalline growth of PLA [54].

\subsection{Isothermal Crystallization Kinetics}

Isothermal crystallization analysis was performed to study the effect of CNF nucleation and PLA-g-MA compatibilization at different PLA-g-MA content on the crystallization rate of PLA reinforced with $3 \mathrm{wt} . \%$ of CNF. DSC curves of isothermal crystallization for neat PLA, PLA/PLA- $g$-MA3/CNF0 and PLA/PLA- $g$-MA/CNF3 nanocomposite samples were presented in Figure 4 . At $\mathrm{T}_{\mathrm{C}}=90,100$ and $110^{\circ} \mathrm{C}$, it is obvious that the crystallization rate of neat PLA is extremely slow where there was no crystallization within the first $100 \mathrm{~min}$. The introduction of PLA-g-MA in the PLA matrix resulted in the appearance of a sharp exothermal peak at an earlier time (60-75 $\mathrm{min})$. Nevertheless, the crystallization took a longer time as compared to PLA/CNF3 (10-30 min) at $\mathrm{T}_{\mathrm{C}}=90,100$ and $110^{\circ} \mathrm{C}$. This may suggest that the addition of PLA- $g$-MA induces the crystallization slightly. In the case of PLA/PLA-g-MA/CNF3, it was observed that the time taken for complete crystallization was longer with increased amount of PLA-g-MA.

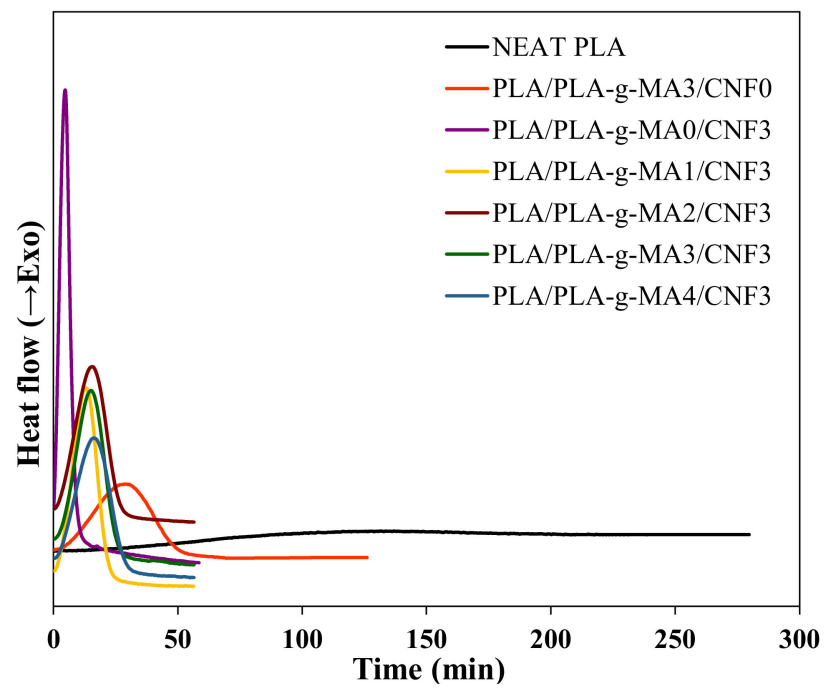

(a)

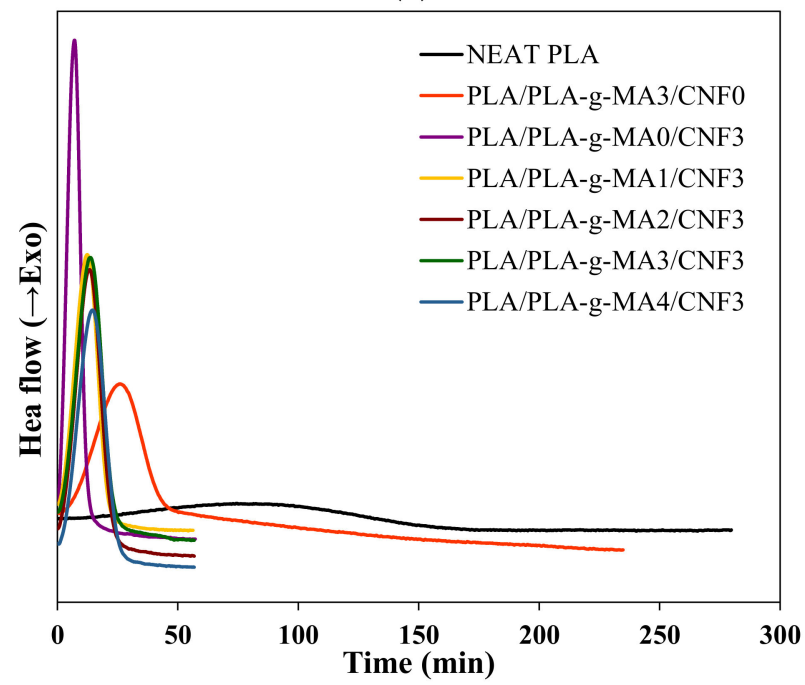

(b)

Figure 4. Cont. 


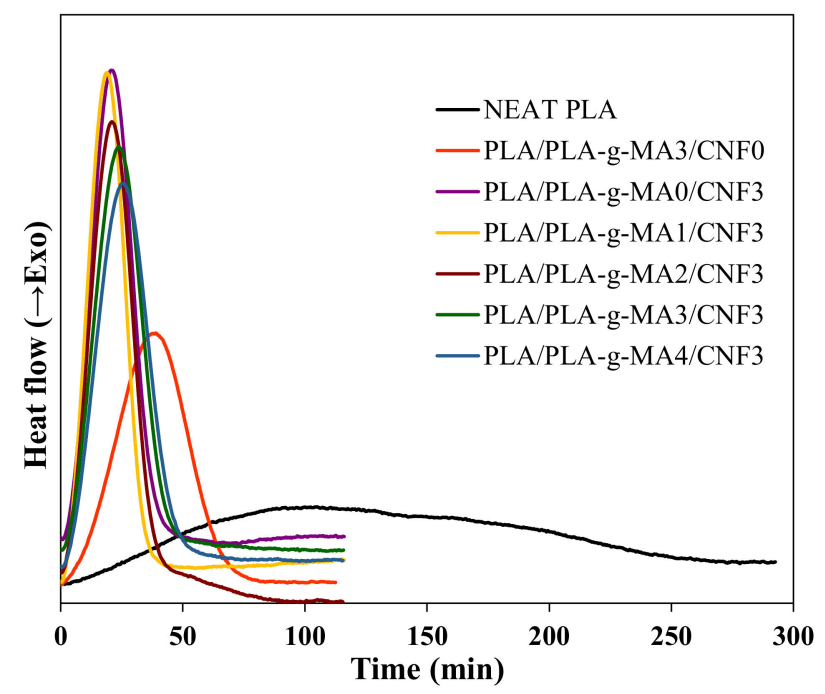

(c)

Figure 4. Isothermal crystallization isotherms of neat PLA, PLA/PLA- $g-M A 3 / C N F 0$ and PLA/PLA$g$-MA/CNF3 nanocomposites at (a) 90, (b) 100 and (c) $110{ }^{\circ} \mathrm{C}$.

To analyze the isothermal crystallization kinetics, the isothermal DSC curves were integrated between $\mathrm{t}=0$ and $\mathrm{t}$ and divided by the overall crystallization rate to calculate the relative degree of crystallinity as follows:

$$
X_{\text {rel }}=\frac{\int_{0}^{t} \frac{d H(t)}{d t} d t}{\int_{0}^{\infty} \frac{d H(t)}{d t} d t}
$$

Avrami equation was used to study the isothermal melt crystallization kinetics where the relative degree of crystallinity $\left(X_{\text {rel }}\right)$ was described as follows:

$$
\mathrm{X}_{\text {rel }}(\mathrm{t})=1-\exp \left(-\mathrm{kt}^{\mathrm{n}}\right)
$$

where $\mathrm{n}$ is the Avrami exponent that depends on the nature of the nucleation mechanism and growth geometry of the crystal, $\mathrm{k}$ is the crystallization rate constant that involves both nucleation and growth rate parameters and $t$ is time. Equation (5) can be transformed into the double-logarithmic form,

$$
\log \left[-\ln \left(1-\mathrm{X}_{\text {rel }}(\mathrm{t})\right)\right]=\log \mathrm{k}+\mathrm{n} \log \mathrm{t}
$$

where the parameters $\mathrm{n}$ (slope) and $\mathrm{k}$ (y-intercept) were determined by plotting $\log$ [ $-\mathrm{ln}$ $\left.\left(1-X_{\text {rel }}(t)\right)\right]$ against $\log t$. Figures 5 and 6 show the $X_{t}$ versus $t$ and Avrami plots for neat PLA, PLA/PLA- $g$-MA3/CNF0 and PLA/PLA- $g$-MA/CNF3 nanocomposites containing different PLA-g-MA content isothermally melt-crystallized at 90,100 and $110{ }^{\circ} \mathrm{C}$. The crystallization half time $\mathrm{t}_{1 / 2}$ is another important crystallization kinetics parameter, which is defined as the time required to achieve $50 \%$ of the final crystallinity of the samples was calculated by the following equation:

$$
\mathrm{t}_{1 / 2}=\left(\frac{\ln 2}{\mathrm{k}}\right)^{\frac{1}{n}}
$$




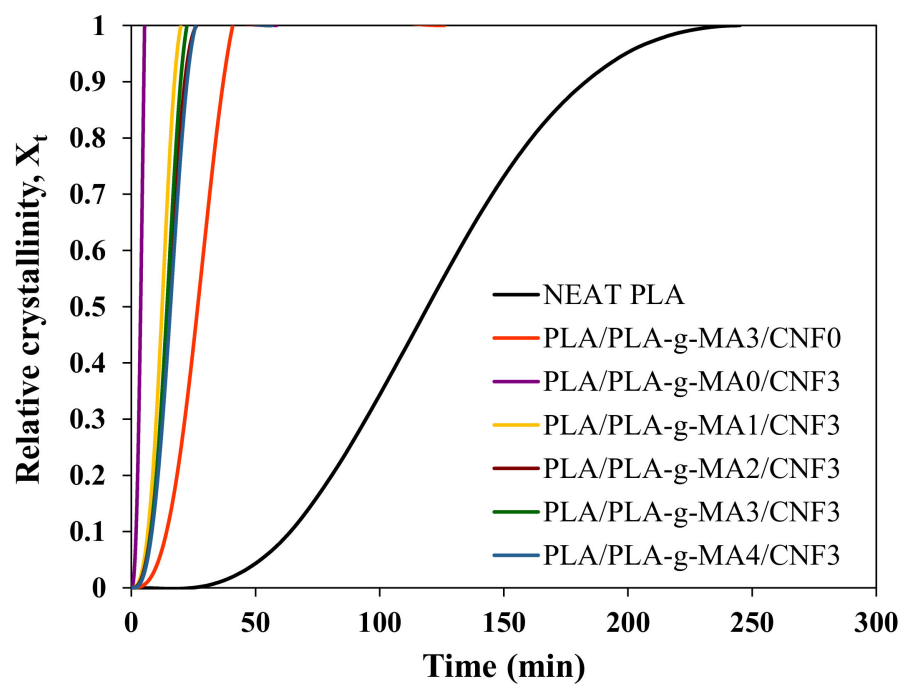

(a)

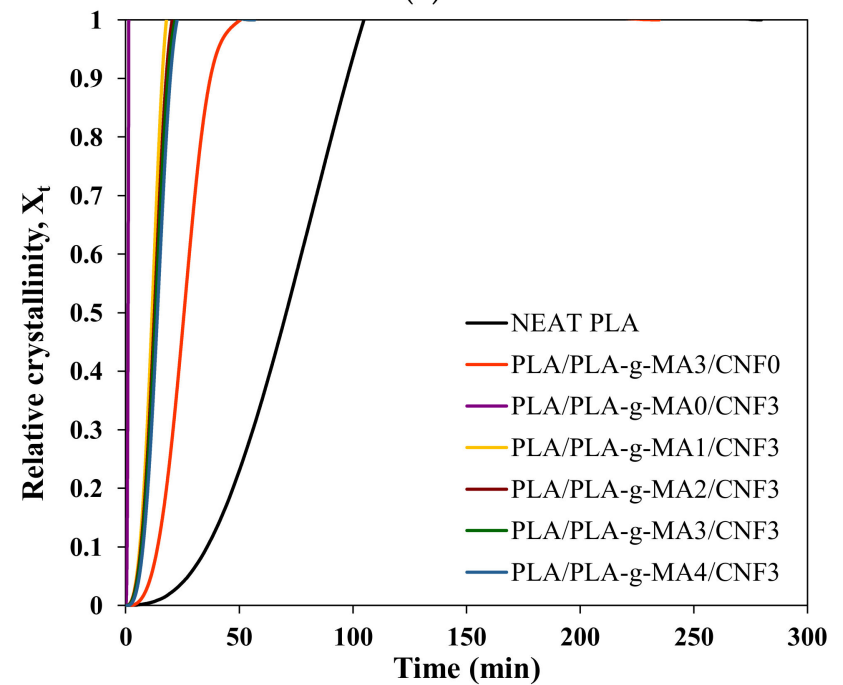

(b)

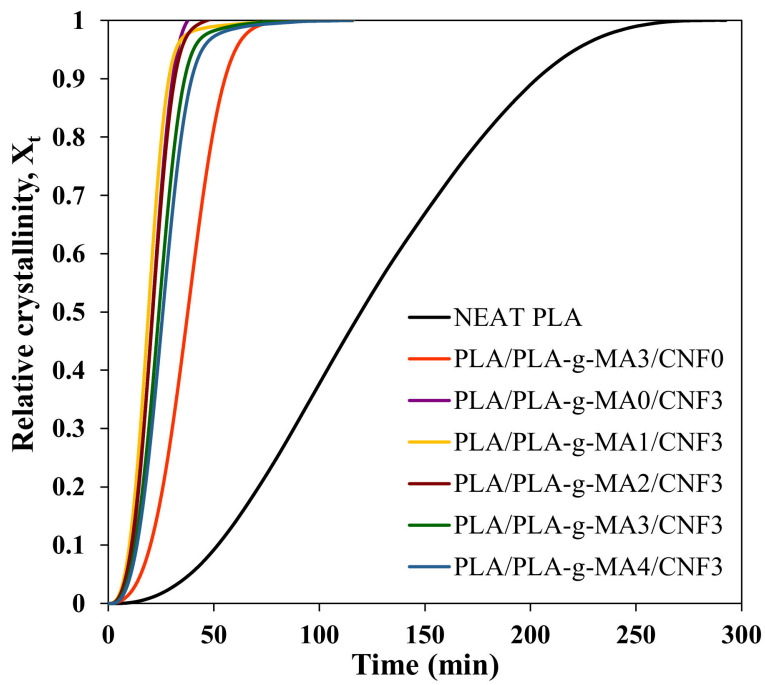

(c)

Figure 5. The relative crystallinity of neat PLA, PLA/PLA- $g-M A 3 / C N F 0$ and PLA/PLA- $g$ MA/CNF3 nanocomposites at (a) 90, (b) 100 and (c) $110{ }^{\circ} \mathrm{C}$. 


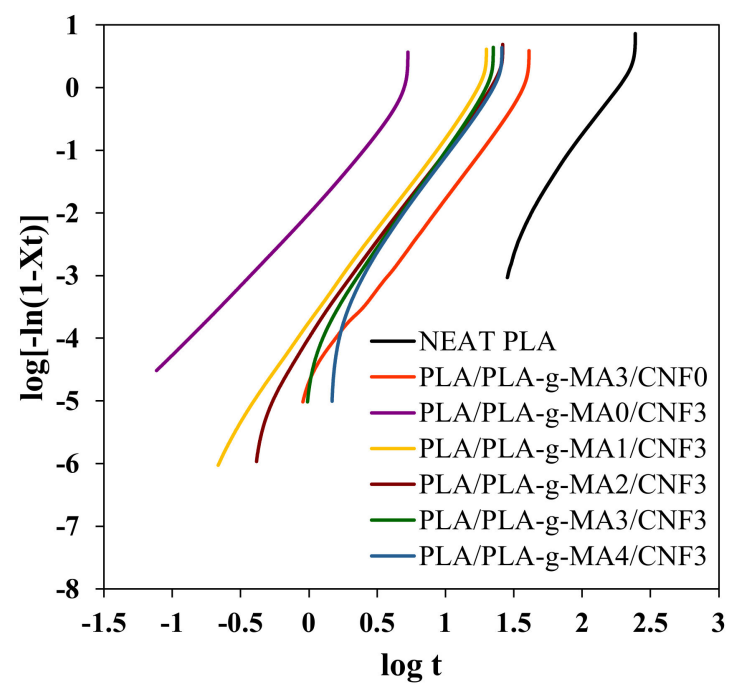

(a)

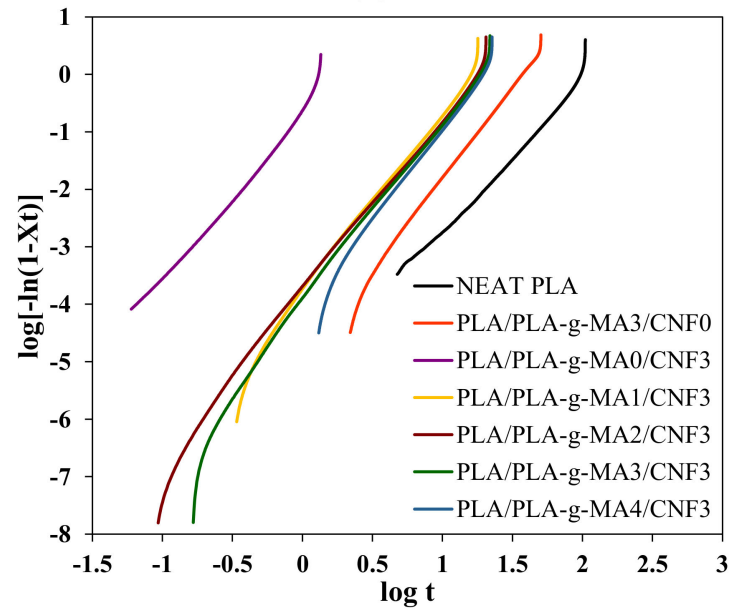

(b)

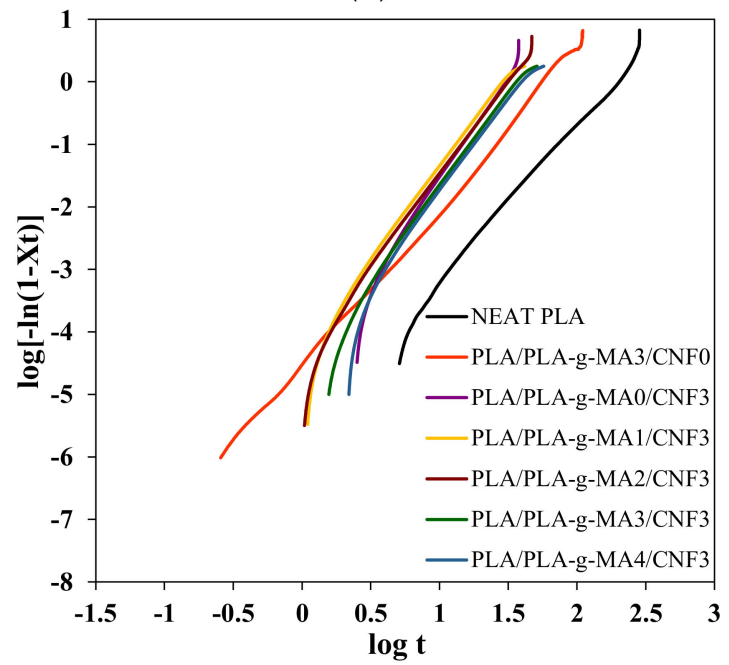

(c)

Figure 6. Avrami plots of neat PLA, PLA/PLA- $g$-MA3/CNF0 and PLA/PLA-g-MA/CNF3 nanocomposites isothermally crystallized at (a) 90 , (b) 100 and (c) $110{ }^{\circ} \mathrm{C}$. 
Generally, the crystallization rates are expressed through the use of crystallization half time. It can be calculated by the reciprocal of $t_{1 / 2}$.

$$
\text { Crystallization rate }=\frac{1}{t_{1 / 2}}
$$

Avrami parameters calculated from the slopes and interceptions of the Avrami plots in Figure 6 are summarized in Table 5 . As seen from the table, the $n$ values for neat PLA were 2.46-3.22. PLA/PLA-g-MA3/CNF0 and PLA/PLA-g-MA0/CNF3 showed $n$ values around 2.67-3.21 and 2.59-3.34 that indicates the addition of PLA-g-MA or CNF did not change the crystallization mechanism and the crystal geometry growth of PLA. As compared to uncompatibilized PLA/CNF3, the compatibilized PLA/CNF3 nanocomposites exhibited a narrowed range of $n$ values between 2.94-3.27 indicates that the addition of PLA-g-MA had a compatibilization effect on the nanocomposites blend [55]. Besides, the $k$ value for all the nanocomposite samples increased with the $T_{c}$ and then decreased after reaching a maximum value at $100{ }^{\circ} \mathrm{C}$ due to the difficulty of crystal nucleation at an elevated temperature [56].

Table 5. Avrami parameters for isothermal crystallization of neat PLA, PLA/PLA-g-MA3/CNF0 and PLA/PLA- $g$ MA/CNF3 nanocomposites.

\begin{tabular}{|c|c|c|c|c|c|c|c|c|c|c|c|c|}
\hline \multirow{2}{*}{ Sample } & \multicolumn{4}{|c|}{$\mathrm{Tc}=90^{\circ} \mathrm{C}$} & \multicolumn{4}{|c|}{$\mathrm{Tc}=100^{\circ} \mathrm{C}$} & \multicolumn{4}{|c|}{$\mathrm{Tc}=110^{\circ} \mathrm{C}$} \\
\hline & $\mathbf{n}$ & $k\left(\min ^{-n}\right)$ & $\begin{array}{c}t_{1 / 2} \\
(\mathrm{~min})\end{array}$ & $\begin{array}{c}1 / t_{1 / 2} \\
\left(\min ^{-1}\right)\end{array}$ & $\mathbf{n}$ & $k\left(\min ^{-n}\right)$ & $\begin{array}{c}t_{1 / 2} \\
(\mathrm{~min})\end{array}$ & $\begin{array}{c}1 / t_{1 / 2} \\
\left(\min ^{-1}\right)\end{array}$ & $\mathbf{n}$ & $k\left(\min ^{-n}\right)$ & $\begin{array}{c}t_{1 / 2} \\
(\mathrm{~min})\end{array}$ & $\begin{array}{c}1 / t_{1 / 2} \\
\left(\min ^{-1}\right)\end{array}$ \\
\hline Neat PLA & 3.22 & $5.72 \times 10^{-8}$ & 158.01 & 0.006 & 2.74 & $2.83 \times 10^{-6}$ & 92.72 & 0.011 & 2.46 & $2.46 \times 10^{-6}$ & 165.59 & 0.006 \\
\hline PLA/PLA- $g-\mathrm{MA} 3 / \mathrm{CNF} 0$ & 2.98 & $1.82 \times 10^{-5}$ & 34.27 & 0.029 & 3.21 & $9.18 \times 10^{-6}$ & 33.22 & 0.030 & 2.67 & $1.90 \times 10^{-5}$ & 51.33 & 0.019 \\
\hline PLA/PLA- $g$-MA0/CNF3 & 2.59 & $1.09 \times 10^{-2}$ & 4.99 & 0.200 & 3.11 & $2.45 \times 10^{-1}$ & 1.40 & 0.716 & 3.34 & $1.20 \times 10^{-5}$ & 26.63 & 0.038 \\
\hline PLA/PLA- $g$-MA1/CNF3 & 3.04 & $1.60 \times 10^{-4}$ & 15.73 & 0.064 & 3.12 & $1.62 \times 10^{-4}$ & 14.64 & 0.068 & 2.95 & $4.63 \times 10^{-5}$ & 26.06 & 0.038 \\
\hline PLA/PLA- $g-M A 2 / C N F 3$ & 3.10 & $9.71 \times 10^{-5}$ & 17.45 & 0.057 & 2.98 & $1.72 \times 10^{-4}$ & 16.15 & 0.062 & 2.99 & $3.30 \times 10^{-5}$ & 28.01 & 0.036 \\
\hline PLA/PLA-g-MA3/CNF3 & 3.27 & $5.53 \times 10^{-5}$ & 17.90 & 0.056 & 3.10 & $1.14 \times 10^{-4}$ & 16.60 & 0.060 & 2.99 & $2.06 \times 10^{-5}$ & 32.63 & 0.031 \\
\hline PLA/PLA- $g$-MA4/CNF3 & 3.21 & $4.79 \times 10^{-5}$ & 19.69 & 0.051 & 3.27 & $5.91 \times 10^{-5}$ & 17.51 & 0.057 & 2.94 & $1.89 \times 10^{-5}$ & 35.75 & 0.028 \\
\hline
\end{tabular}

Other important crystallization kinetics parameters, the crystallization half time $\left(\mathrm{t}_{1 / 2}\right)$ and crystallization rate $\left(1 / t_{1 / 2}\right)$, were calculated using Equations (7) and (8). From Table 5 , the $t_{1 / 2}$ for neat PLA were $158.01,92.72$ and 165.59 , respectively, when isothermally crystallized at 90,100 and $110^{\circ} \mathrm{C}$. By solely adding PLA-g-MA to PLA blend, the $t_{1 / 2}$ was reduced to $34.27,33.22$ and $51.33 \mathrm{~min}$. These results show that the functionality of PLA-g-MA was not solely as a compatibilizer, but it also assisted in early nucleation. Although PLA-g-MA contributes to slow nucleation rate at the beginning, but once the nuclei was nucleated, it promotes rapid crystal growth as can be observed in steep sigmoidal shape of $X_{t}$ vs. t plot of PLA/PLA-g-MA3/CNF0 as compared to neat PLA (Figure 5).

Both the nucleation and crystal growth processes were however better with the addition of CNF. As shown in Figure $7 \mathrm{a}, \mathrm{b}$, the lowest $\mathrm{t}_{1 / 2}$ and the highest crystallization rate are seen when $0 \%$ PLA- $g$-MA was used. All PLA/PLA-g-MA/CNF3 nanocomposites showed higher crystallization rate as compared to PLA/PLA-g-MA. As seen in Table 5 and Figure 7a, the addition of PLA- $g$-MA from 1 to $4 \mathrm{wt}$.\% increases the $t_{1 / 2}$ values to 19.69, 17.51 and $35.75 \mathrm{~min}$ from $4.99,1.40$ and $26.63 \mathrm{~min}$ of the PLA/PLA-g-MA0/CNF3, respectively, when isothermally melt-crystallized at 90,100 and $110{ }^{\circ} \mathrm{C}$. These findings indicate that PLA-g-MA might be a chain extender between PLA and CNF, resulting in longer polymer chains and higher chain rigidity [57]. As a result, the crystallization half time increased (i.e., $1 / t_{1 / 2}$ decreased) with the addition of PLA- $g$-MA. Among the $T_{c}$ investigated, more distinct nucleation effects with a minimum $t_{1 / 2}$ value can be seen at $T_{C}=100{ }^{\circ} \mathrm{C}$ for all nanocomposites. This temperature corresponds to the optimum temperature of isothermal crystallization of the nanocomposites similar in PLA/CNF study previously conducted [45]. A similar trend can be seen for crystallization rate as shown in Figure $7 \mathrm{~b}$, which shows that the highest crystallization rate was observed for PLA/PLA-g-MA0/CNF3 nanocomposites. 


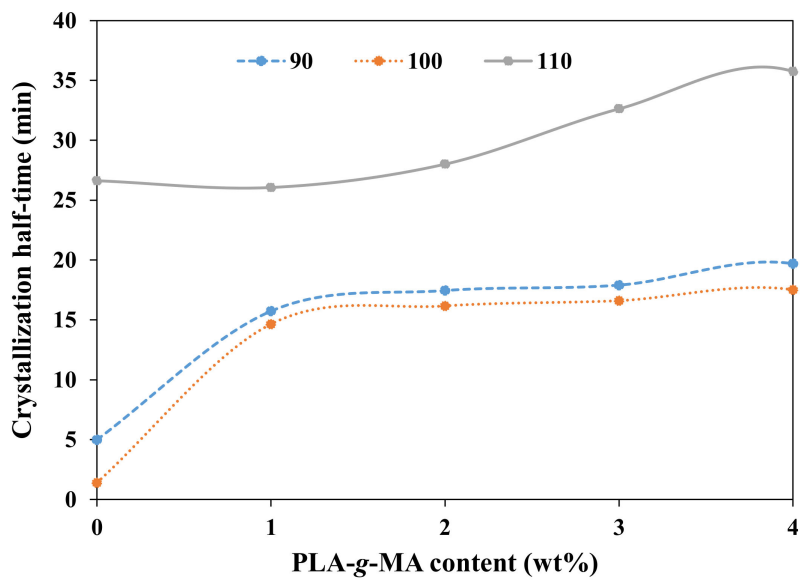

(a)

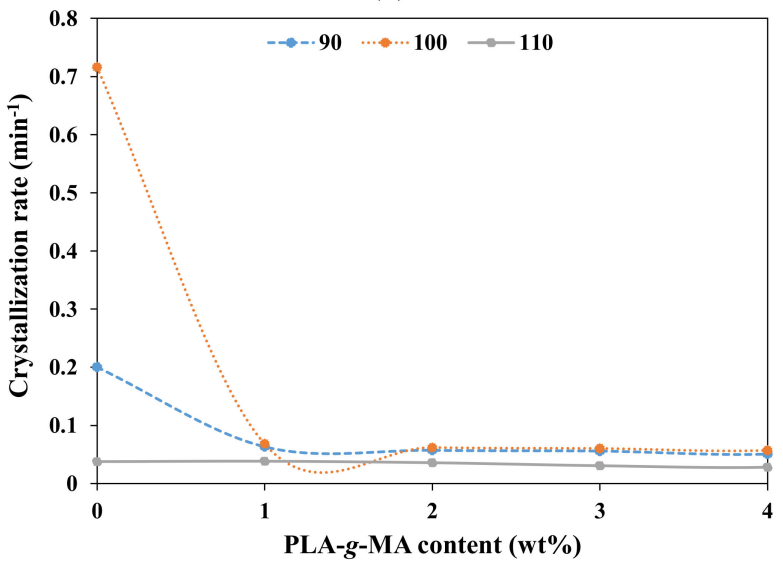

(b)

Figure 7. Dependence of (a) crystallization half-time and (b) crystallization rate on PLA-g-MA content for PLA reinforced $3 \mathrm{wt} . \%$ CNF melt-crystallized isothermally at 90,100 and $110{ }^{\circ} \mathrm{C}$.

Based on the above findings, it can be summarized that despite nucleation effect of PLA-g-MA, the effect is not as superior as CNF. Among all, uncompatibilized PLA/CNF3 exhibited the best crystallization rate, suggesting that the presence of PLA-g-MA is not necessary for the improvement of crystallization rate of the PLA/CNF nanocomposites.

\subsection{Mechanical Properties}

Mechanical testing was performed to evaluate the nucleation and compatibilization effects of CNF and PLA-g-MA on the mechanical properties of PLA/PLA- $g$-MA/CNF nanocomposites. The results for neat PLA, PLA/PLA-g-MA3/CNF0 and PLA/PLA- $g$ MA/CNF3 nanocomposites are tabulated in Table 6.

Table 6. Mechanical properties of neat PLA, PLA/PLA-g-MA3/CNF0 and PLA/PLA-g-MA/CNF3 nanocomposites.

\begin{tabular}{cccc}
\hline Composition & Tensile Strength (MPa) & Young's Modulus (GPa) & Elongation at Break (\%) \\
\hline Neat PLA & $70.8 \pm 0.1^{\mathrm{b}}$ & $2.9^{\mathrm{b}} \pm 0.0^{\mathrm{f}}$ & $2.54 \pm 0.1^{\mathrm{a}}$ \\
PLA/PLA-g-MA3/CNF0 & $70.0 \pm 0.3^{\mathrm{c}}$ & $11.0 \pm 0.9^{\mathrm{d}}$ & $2.46 \pm 0.4^{\mathrm{b}}$ \\
PLA/PLA-g-MA0/CNF3 & $74.1 \pm 0.1^{\mathrm{a}}$ & $3.3^{\mathrm{a}} \pm 0.1^{\mathrm{e}}$ & $2.34 \pm 0.1^{\mathrm{c}}$ \\
PLA/PLA-g-MA1/CNF3 & $66.1 \pm 0.5^{\mathrm{d}}$ & $11.5^{\mathrm{c}} \pm 0.2^{\mathrm{c}}$ & $2.17 \pm 0.3^{\mathrm{d}}$ \\
PLA/PLA-g-MA2/CNF3 & $65.9 \pm 0.8^{\mathrm{d}, \mathrm{e}}$ & $11.6 \pm 0.1^{\mathrm{c}}$ & $2.14 \pm 0.1^{\mathrm{d}}$ \\
PLA/PLA-g-MA3/CNF3 & $65.7 \pm 0.1^{\mathrm{e}}$ & $11.7^{\mathrm{e}} \pm 0.4^{\mathrm{b}, \mathrm{c}}$ & $2.11 \pm 0.1^{\mathrm{e}}$ \\
PLA/PLA-g-MA4/CNF3 & $65.5 \pm 0.2^{\mathrm{e}}$ & $11.8 \pm 0.1^{\mathrm{b}, \mathrm{c}}$ & $2.05 \pm 0.3^{\mathrm{f}}$ \\
\hline
\end{tabular}

All data are means of 5 replicates \pm S.D. The alphabets indicate significant difference $(p<0.05)$ according to Duncan's Multiple Range Test. 
Overall, it is seen that the addition of PLA-g-MA increased the Young's modulus of the PLA, without affecting the tensile strength and elongation at break. Young's modulus is typically related to the stiffness of the polymer where a more rigid polymer exhibits higher modulus. As seen from Table 6, the Young's modulus for neat PLA was 2.9 GPa. In comparison to neat PLA, PLA/PLA- $g$-MA3 had much higher Young's modulus by $280 \%$. As discussed earlier, the addition of PLA- $g-\mathrm{MA}$ contributed to the restriction of molecular motion when anhydride carboxyl group was grafted onto the PLA. This increases the nanocomposites rigidity, which is being reflected through the high Young's modulus value [17]. The Young's modulus recorded was also higher compared to uncompatibilized PLA/CNF3. In the case of PLA/PLA- $g$-MA/CNF3 nanocomposites, it is seen from Table 6 that the Young's modulus value increased with the PLA-g-MA concentration. Elongation at break reduced as opposed to Young's modulus since rigid material is expected to have lower elongation.

In terms of tensile strength, it is seen that the addition of PLA- $g$-MA slightly reduced the tensile strength. The tensile strength continued to reduce in PLA/PLA-g-MA/CNF3 with the increasing amount of PLA- $g$-MA. This could be attributed to the low molecular weight PLA-g-MA [18,43]. PLA/CNF3 without PLA-g-MA, on the other hand, had a higher tensile strength of PLA/PLA- $g$-MA3. The reinforcement of CNF in PLA matrix without the presence of PLA- $g$-MA significantly increased the strength due to a superior transfer of load from PLA matrix to the CNF, as reported by Abdulkhani et al. [58,59] and Ghasemi et al. [44]. The addition of the PLA-g-MA as a compatibilizer is expected to improve the interfacial adhesion between CNF and PLA matrix; however, the tensile strength of the nanocomposites gradually decreased as PLA-g-MA content increased.

\subsection{Morphological Analysis}

The morphologies of the fractured surfaces of the nanocomposites, i.e., neat PLA (Figure 8a), PLA/PLA-g-MA3/CNF0 (Figure 8b), PLA/PLA-g-MA0/CNF3 (Figure 8c) and PLA/PLA-g-MA3/CNF3 (Figure 8d) are shown, respectively.
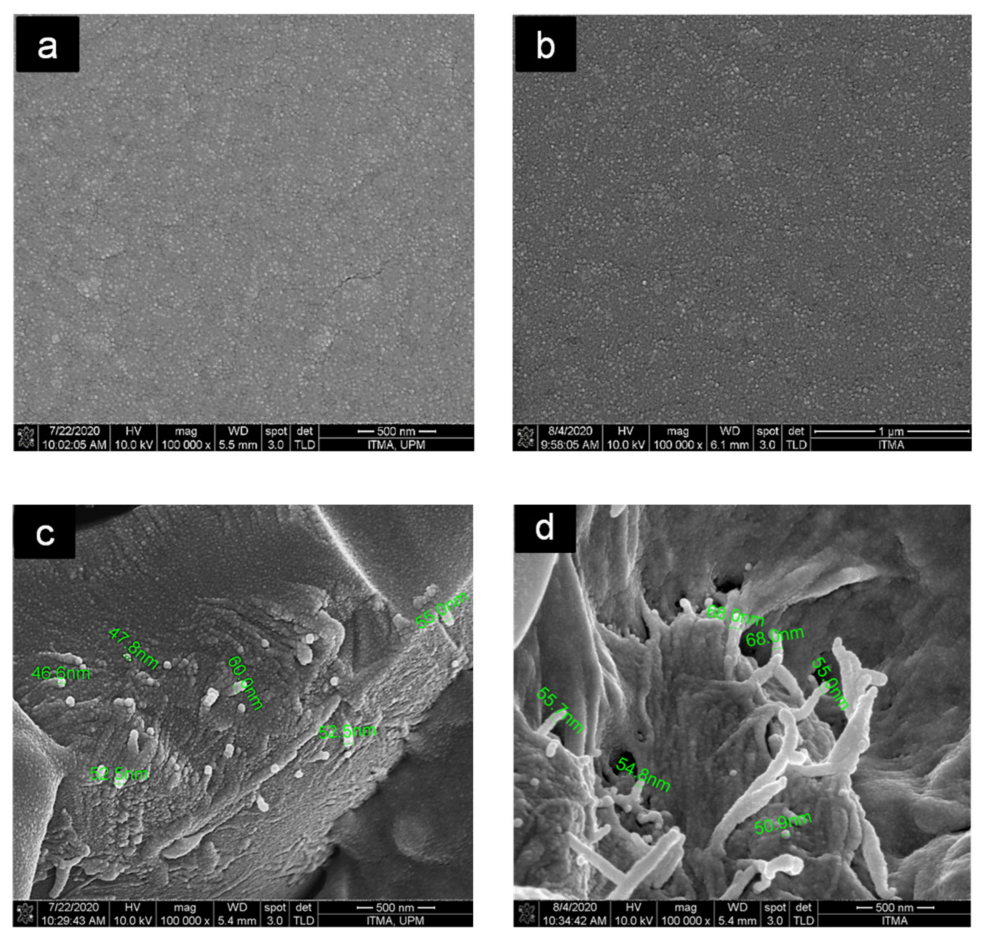

Figure 8. FESEM micrographs of the fractured surfaces of (a) neat PLA, (b) PLA/PLA- $g$-MA3/CNF0, (c) PLA/PLA- $g$-MA0/CNF3 and (d) PLA/PLA- $g-M A 3 / C N F 3$ nanocomposites at 100,000 $\times$ magnification. 
As seen from Figure 8a,b, a relatively smooth surface can be seen in neat PLA, and PLA/PLA-g-MA3/CNF0 indicated the brittle failure characteristics, as the fractures showed little sign of plastic deformation [60]. Moreover, the addition of PLA-g-MA did not affect the structure of PLA. For PLA/PLA-g-MA0/CNF3, some fiber breakages on the fractured surface could be observed, and no agglomeration can be detected indicates that the CNF was well-blended in PLA matrix even without the presence of PLA- $g$-MA, thus resulted in higher tensile strength than other nanocomposites. For the compatibilized nanocomposites with the same CNF content, the addition of PLA-g-MA in the nanocomposites did not seem to affect the samples structure. It was proven that PLA-g-MA can also act as a plasticizer in the nanocomposite blends due to the reduction trend of $\mathrm{T}_{\mathrm{g}}$ and tensile strength as discussed previously in Sections 3.2 and 3.4.

\section{Conclusions}

The influence of PLA-g-MA on nucleating effect of CNF was determined by studying the effect of various PLA- $g$-MA wt.\% addition on the crystallization kinetics of PLA/PLA$g$-MA/CNF3. Data from isothermal crystallization kinetic study at $\mathrm{T}_{\mathrm{C}}=100{ }^{\circ} \mathrm{C}$ showed that the crystallization rate increased from 0.011 to $0.030 \mathrm{~min}^{-1}$ as compared to the neat PLA. This shows that PLA-g-MA had some effect on the nucleation, even though not as effective as the CNF. When PLA-g-MA was added to PLA/CNF3, it was shown that the crystallization rate of the PLA/PLA-g-MA/CNF3 decreased as compared to uncompatibilized PLA/CNF3. This shows that the addition of PLA-g-MA in PLA/CNF3 was ineffective and unnecessary in improving crystallization kinetics of PLA nanocomposites. Reinforcement of $3 \mathrm{wt} . \%$ CNF with the combination of PLA-g-MA (1-4 wt.\%) in PLA matrix reduced the tensile strength of PLA, but increased the Young's modulus. Findings from this research revealed that the addition of PLA- $g$-MA did not affect the crystallization property of the PLA/CNF nanocomposites, but only affected the mechanical properties of the nanocomposite samples. Research on the synergistic mechanism of nucleation between CNF and PLA-g-MA in the kinetics of biopolymer biodegradation is currently in progress.

Author Contributions: The manuscript was completed through the contributions of all authors. Conceptualization, H.A.; data curation, S.S.S.; formal analysis, S.S.S.; funding acquisition, H.A.; investigation, S.S.S.; methodology, S.S.S.; supervision, N.A.I., M.A.H. and H.A.; validation, H.A.; writing-original draft, S.S.S.; writing-review and editing, H.A., L.Y.F.N. All authors have read and agreed to the published version of the manuscript.

Funding: This research was funded by the Ministry of Education (MOE), through FRGS research grant number 5540321 (FRGS/1/2019/TK05/UPM/02/1).

Institutional Review Board Statement: Not applicable.

Informed Consent Statement: Not applicable.

Conflicts of Interest: The authors declare no conflict of interest.

\section{References}

1. Bari, S.S.; Chatterjee, A.; Mishra, S. Biodegradable polymer nanocomposites: An overview. Polym. Rev. 2016, 56, 287-328. [CrossRef]

2. Hu, B. Biopolymer-based lightweight materials for packaging applications. ACS Symp. Ser. 2014, 1175, 239-255. [CrossRef]

3. Pawar, P.A.; Purwar, A.H. Bioderadable Polymers in Food Packaging. Am. J. Eng. Res. 2013, 2, $151-164$.

4. Bratovcic, A.; Odobasic, A.; Catic, S.; Sestan, I. Application of polymer nanocomposite materials in food packaging. Croat. J. Food Sci. Technol. 2015, 7, 86-94. [CrossRef]

5. Jun, C.L. Reactive Blending of Biodegradable Polymers: PLA and Starch. J. Polym. Environ. 2000, 8, 33-37. [CrossRef]

6. Suryanegara, L.; Nakagaito, A.N.; Yano, H. The effect of crystallization of PLA on the thermal and mechanical properties of microfibrillated cellulose-reinforced PLA composites. Compos. Sci. Technol. 2009, 69, 1187-1192. [CrossRef]

7. Verma, D.; Fortunati, E. Biobased and biodegradable plastics. In Handbook of Ecomaterials; Springer: Cham, Switzerland, 2019; Volume 4, pp. 2955-2976, ISBN 978-3-319-68255-6.

8. Norio, A.; Fujimura, A.; Sakai, T.; Hama, Y.; Yano, H. Production of microfibrillated cellulose (MFC)-reinforced polylactic acid (PLA) nanocomposites from sheets obtained by a papermaking-like process. Compos. Sci. Technol. 2009, 69, 1293-1297. [CrossRef] 
9. Frone, A.N.; Berlioz, S.; Chailan, J.-F.; Panaitescu, D.M. Morphology and thermal properties of PLA-Cellulose nanofibers composites. Carbohydr. Polym. 2013, 91, 377-384. [CrossRef]

10. Pereira, F.M.; Canevarolo, S.V.; Chinelatto, M.A. Isothermal crystallization kinetics of biodegradable poly(lactic acid)/poly( $\varepsilon-$ caprolactone) blends compatibilized with low-molecular weight block copolymers. Polym. Eng. Sci. 2019, 59, E161-E169. [CrossRef]

11. Chen, Y.; Yao, X.; Gu, Q.; Pan, Z. Non-isothermal crystallization kinetics of poly (lactic acid)/graphene nanocomposites. J. Polym. Eng. 2013, 33, 163-171. [CrossRef]

12. Yang, B.; Wang, D.; Chen, F.; Su, L.F.; Miao, J.B.; Chen, P.; Qian, J.S.; Xia, R.; Liu, J.W. Melting and Crystallization Behaviors of Poly(Lactic Acid) Modified with Graphene Acting as a Nucleating Agent. J. Macromol. Sci. Part B Phys. 2019, 58, 290-304. [CrossRef]

13. Cipriano, T.F.; Silva, A.L.N.D.; Silva, A.H.M.D.F.T.D.; Sousa, A.M.F.D.; Silva, G.M.D.; Rocha, M.G. Thermal, Rheological and Morphological Properties of Poly (Lactic Acid) (PLA) and Talc Composites. Polímeros 2014, 24, 276-282. [CrossRef]

14. Fowlks, A.C.; Narayan, R. The Effect of Maleated Polylactic Acid (PLA) as an Interfacial Modifier in PLA-Talc Composites. J. Appl. Polym. Sci. 2010, 118, 2810-2820. [CrossRef]

15. Refaa, Z.; Boutaous, M.; Rousset, F.; Fulchiron, R.; Zinet, M.; Xin, S.; Bourgin, P. Crystallization kinetics of poly-(lactic acid) with and without talc: Optical microscopy and calorimetric analysis. AIP Conf. Proc. 2014, 1593, 342-346. [CrossRef]

16. Jia, W.; Gong, R.H.; Hogg, P.J. Poly(lactic acid) fibre reinforced biodegradable composites. Compos. Part B 2014, 62, 104-112. [CrossRef]

17. $\mathrm{Wu}, \mathrm{C}$. Renewable resource-based composites of recycled natural fibers and maleated polylactide bioplastic: Characterization and biodegradability. Polym. Degrad. Stab. 2009, 94, 1076-1084. [CrossRef]

18. Yu, T.; Jiang, N.; Li, Y. Study on short ramie fiber/poly (lactic acid) composites compatibilized by maleic anhydride. Compos. Part A 2014, 64, 139-146. [CrossRef]

19. Zhang, Q.; Shi, L.; Nie, J.; Wang, H.; Yang, D. Study on Poly (lactic acid)/Natural Fibers Composites. J. Appl. Polym. Sci. 2012, 125, E526-E533. [CrossRef]

20. Jonoobi, M.; Harun, J.; Mathew, A.P.; Oksman, K. Mechanical properties of cellulose nanofiber (CNF) reinforced polylactic acid (PLA) prepared by twin screw extrusion. Compos. Sci. Technol. 2010, 70, 1742-1747. [CrossRef]

21. Hubbe, M.A.; Rojas, O.J.; Lucia, L.A.; Sain, M. Cellulosic Nanocomposites: A Review. BioResources 2008, 3, 929-980. [CrossRef]

22. Manocha, L.M.; Valand, J.; Patel, N.; Warrier, A.; Manocha, S. Nanocomposites for structural applications. Indian J. Pure Appl. Phys. 2006, 44, 135-142.

23. Pandey, J.K.; Ahn, S.H.; Lee, C.S.; Mohanty, A.K.; Misra, M. Recent advances in the application of natural fiber based composites. Macromol. Mater. Eng. 2010, 295, 975-989. [CrossRef]

24. Panthapulakkal, S.; Sain, M. Preparation and characterization of cellulose nanofibril films from wood fibre and their thermoplastic polycarbonate composites. Int. J. Polym. Sci. 2012, 2012. [CrossRef]

25. Tang, C.; Liu, H. Cellulose nanofiber reinforced poly(vinyl alcohol) composite film with high visible light transmittance. Compos. Part A Appl. Sci. Manuf. 2008, 39, 1638-1643. [CrossRef]

26. Wang, B.; Sain, M. The effect of chemically coated nanofiber reinforcement on biopolymer based nanocomposites. BioResources 2007, 2, 371-388.

27. Wei, H.; Rodriguez, K.; Renneckar, S.; Vikesland, P.J. Environmental science and engineering applications of nanocellulose-based nanocomposites. Environ. Sci. Nano 2014, 1, 302-316. [CrossRef]

28. Zimmermann, T.; Bordeanu, N.; Strub, E. Properties of nanofibrillated cellulose from different raw materials and its reinforcement potential. Carbohydr. Polym. 2010, 79, 1086-1093. [CrossRef]

29. Kiziltas, A.; Nazari, B.; Gardner, D.J.; Bousfield, D.W. Polyamide 6-Cellulose Composites: Effect of Cellulose Composition on Melt Rheology and Crystallization Behavior. Polym. Eng. Sci. 2014, 54, 739-746. [CrossRef]

30. Kose, R.; Kondo, T. Size effects of cellulose nanofibers for enhancing the crystallization of poly(lactic acid). J. Appl. Polym. Sci. 2013, 128, 1200-1205. [CrossRef]

31. Suryanegara, L.; Nakagaito, A.N.; Yano, H. Thermo-mechanical properties of microfibrillated cellulose-reinforced partially crystallized PLA composites. Cellulose 2010, 17, 771-778. [CrossRef]

32. Song, Y.; Tashiro, K.; Xu, D.; Liu, J.; Bin, Y. Crystallization behavior of poly (lactic acid)/microfibrillated cellulose composite. Polymer 2013, 54, 3417-3425. [CrossRef]

33. Ariffin, H.; Yasim, T.A.T.; Amadi, N.I.; Nadia, F. Characterization of Cellulose Nanofiber From Various Tropical Plant Resources. In Lignocellulose for Future Bioeconomy; Elsevier: Amsterdam, The Netherlands, 2019; pp. 71-90, ISBN 9780128163542.

34. Hussin, M.H.; Trache, D.; Chuin, C.T.H.; Fazita, M.R.N.; Haafiz, M.K.M.; Hossain, M.S. Extraction of Cellulose Nano fi bers and Their Eco-friendly Polymer Composites. In Sustainable Polymer Composites and Nanocomposites; Inamuddin, T.S., Mishra, R.K., Asiri, A.M., Eds.; Springer: Cham, Switzerland, 2019; pp. 653-691, ISBN 9783030053994.

35. Ghasemi, S.; Behrooz, R.; Ghasemi, I. Investigating the properties of maleated poly(lactic acid) and its effect on poly (lactic acid)/cellulose nanofiber composites. J. Polym. Eng. 2017, 38, 1-8. [CrossRef]

36. Gunning, M.A.; Geever, L.M.; Killion, J.A.; Lyons, J.G.; Higginbotham, C.L. Improvement in Mechanical Properties of Grafted Polylactic Acid Composite Fibers via Hot Melt Extrusion. Polym. Compos. 2008, 16, 101-113. [CrossRef] 
37. Calderón, B.A.; Soule, J.; Sobkowicz, M.J. Synthesis and characterization of compatibilizers for blends of polypropylene carbonate and polybutylene succinate via free-radical grafting of maleic anhydride. Appl. Polym. Sci. 2019, 47553, 1-13. [CrossRef]

38. Zhang, J.; Sun, X. Mechanical and Thermal Properties of Poly (lactic acid)/Starch Blends with Dioctyl Maleate. J. Appl. Polym. Sci. 2004. [CrossRef]

39. Phetwarotai, W.; Potiyaraj, P.; Aht-ong, D. Properties of Compatibilized Polylactide Blend Films with Gelatinized Corn and Tapioca Starches. J. Appl. Polym. Sci. 2010, 116, 2305-2311. [CrossRef]

40. Wang, H.; Sun, X.; Seib, P. Strengthening Blends of Poly (lactic acid) and Starch with Methylenediphenyl Diisocyanate. J. Appl. Microbiol. 2001, 82, 1761-1767. [CrossRef]

41. Wang, H.; Sun, X.; Seib, P. Effects of Starch Moisture on Properties of Wheat Starch/Poly (Lactic Acid) Blend Containing Methylenediphenyl. J. Polym. Environ. 2002, 10, 1-6. [CrossRef]

42. Nguyen, T.C.; Ruksakulpiwat, C.; Ruksakulpiwat, Y. Effect of cellulose nanofibers from cassava pulp on physical properties of poly(lactic acid) biocomposites. J. Thermoplast. Compos. Mater. 2019, 33, 1094-1108. [CrossRef]

43. Rigolin, T.R.; Takahashi, M.C.; Kondo, D.L.; Bettini, S.H.P. Compatibilizer Acidity in Coir-Reinforced PLA Composites: Matrix Degradation and Composite Properties. J. Polym. Environ. 2019, 27, 1096-1104. [CrossRef]

44. Ghasemi, S.; Behrooz, R.; Ghasemi, I.; Yassar, R.S.; Long, F. Development of nanocellulose-reinforced PLA nanocomposite by using maleated PLA (PLA-g-MA). J. Thermoplast. Compos. Mater. 2018, 31, 1090-1101. [CrossRef]

45. Shazleen, S.S.; Yasim-Anuar, T.A.T.; Ibrahim, N.A.; Hassan, M.A.; Ariffin, H. Functionality of Cellulose Nanofiber as Bio-Based Nucleating Agent and Nano-Reinforcement Material to Enhance Crystallization and Mechanical Properties of Polylactic Acid Nanocomposite. Polymers 2021, 13, 389. [CrossRef]

46. Birnin-yauri, A.U.; Ibrahim, N.A.; Zainuddin, N.; Abdan, K.; Then, Y.Y.; Chieng, B.W. Effect of Maleic Anhydride-Modified Poly (lactic acid) on the Properties of Its Hybrid Fiber Biocomposites. Polymers 2017, 9, 165. [CrossRef]

47. Ma, P.; Jiang, L.; Ye, T.; Dong, W.; Chen, M. Melt Free-Radical Grafting of Maleic Anhydride onto Biodegradable Poly(lactic acid) by Using Styrene as a Comonomer. Polymer 2014, 6, 1528-1543. [CrossRef]

48. Syazana, N.; Sani, A.; Arsad, A.; Rahmat, A.R. Synthesis of a compatibilizer and the effects of monomer concentrations. Appl. Mech. Mater. 2014, 554, 96-100. [CrossRef]

49. Muenprasat, D.; Suttireungwong, S.; Tongpin, C. Functionalization of Poly (Lactic Acid) with Maleic Anhydride for Biomedical Application. J. Met. Mater. Miner. 2010, 20, 189-192.

50. Ahmad, E.E.M.; Luyt, A.S. Morphology, Thermal, and Dynamic Mechanical Properties of Poly(lactic acid)/Sisal Whisker Nanocomposites. Polym. Compos. 2008, 16, 101-113. [CrossRef]

51. González-López, M.E.; Pérez-Fonseca, A.A.; Cisneros-López, E.O.; Manríquez-González, R.; Ramírez-Arreola, D.E.; Rodrigue, D.; Robledo-Ortíz, J.R. Effect of Maleated PLA on the Properties of Rotomolded PLA-Agave Fiber Biocomposites. J. Polym. Environ. 2019, 27, 61-73. [CrossRef]

52. Gross, I.P.; Schneider, F.S.S.; Caro, M.S.B.; da Conceição, T.F.; Caramori, G.F.; Pires, A.T.N. Polylactic acid, maleic anhydride and dicumyl peroxide: NMR study of the free-radical melt reaction product. Polym. Degrad. Stab. 2018, 155, 1-8. [CrossRef]

53. Kotsilkova, R.; Angelova, P.; Batakliev, T.; Angelov, V.; Di Maio, R.; Silvestre, C. Study on Aging and Recover of Poly (Lactic) Acid Composite Films with Graphene and Carbon Nanotubes Produced by Solution Blending and Extrusion. Coatings 2019 , 9, 359. [CrossRef]

54. Nisa, N.; Mohammad, B.; Arsad, A.; Syazana, N.; Sani, A. Effect of Compatibilisers on Thermal and Morphological Properties of Polylactic Acid/Natural Rubber Blends. Chem. Eng. Trans. 2017, 56, 1027-1032. [CrossRef]

55. Zhang, C.; Lan, Q.; Zhai, T.; Nie, S.; Luo, J.; Yan, W. Melt crystallization behavior and crystalline morphology of Polylactide/Poly( $\varepsilon$ caprolactone) blends compatibilized by lactide-caprolactone copolymer. Polymers 2018, 10, 1181. [CrossRef] [PubMed]

56. Rodrigues, A.; Carvalho, B.D.M.; Pinheiro, L.A.; Bretãs, R.E.S.; Canevarolo, S.V.; Marini, J. Effect of Compatibilization and Reprocessing on the Isothermal Crystallization Kinetics of Polypropylene/Wood Flour Composites. Polimeros 2013, 23, 312-319. [CrossRef]

57. Phetwarotai, W.; Aht-Ong, D. Isothermal crystallization behaviors and kinetics of nucleated polylactide/poly(butylene adipateco-terephthalate) blend films with talc: Influence of compatibilizer contents. J. Therm. Anal. Calorim. 2016, 126, 1797-1808. [CrossRef]

58. Abdulkhani, A.; Hosseinzadeh, J.; Ashori, A.; Dadashi, S.; Takzare, Z. Preparation and characterization of modified cellulose nanofibers reinforced polylactic acid nanocomposite. Polym. Test. 2014, 35, 73-79. [CrossRef]

59. Abdulkhani, A.; Hosseinzadeh, J.; Dadashi, S.; Mousavi, M. A study of morphological, thermal, mechanical and barrier properties of PLA based biocomposites prepared with micro and nano sized cellulosic fibers. Cellul. Chem. Technol. 2015, 49, 597-605.

60. Zhu, R.; Liu, H.; Zhang, J. Compatibilizing effects of maleated poly(lactic acid) (PLA) on properties of PLA/soy protein composites. Ind. Eng. Chem. Res. 2012, 51, 7786-7792. [CrossRef] 